\title{
Staphylococcal Sepsis with Multiple Abscesses, Urinary Tract Infection, and Bilateral Renal Vein Thrombosis in a Patient with Uncontrolled Diabetes Mellitus
}

\author{
Malik A. A. Khan, ${ }^{1}$ Jonathan Michael Hunter, ${ }^{1,2}$ Christopher Tan, ${ }^{2}$ \\ Mostafa Seleem, ${ }^{2}$ and Peter J. O. Stride ${ }^{1,2}$ \\ ${ }^{1}$ The School of Medicine, University of Queensland, Brisbane, QLD 4072, Australia \\ ${ }^{2}$ Department of Medicine, Redcliffe Hospital, Locked Bag One, Redcliffe, QLD 4020, Australia
}

Correspondence should be addressed to Jonathan Michael Hunter, jonhunter@live.com.au

Received 16 July 2012; Accepted 11 September 2012

Academic Editor: Stephen A. Klotz

Copyright (C) 2012 Malik A. A. Khan et al. This is an open access article distributed under the Creative Commons Attribution License, which permits unrestricted use, distribution, and reproduction in any medium, provided the original work is properly cited.

We report a case of staphylococcal sepsis with vascular complications including peripheral emboli and renal vein thrombosis. Bilateral renal vein thrombosis has not been reported as a complication of Staphylococcus aureus (SA) axillary abscess. Uncontrolled diabetes was the only detected predisposing medical condition. The patient was treated successfully with incision and drainage of soft-tissue abscesses and intravenous antibiotic for six weeks and with anticoagulation for renal vein thrombosis.

\section{Case Report}

A 50-year-old male presented to our hospital with two weeks of malaise, polyuria, dysuria, and fever. Physical examination revealed a tender fluctuant left axillary mass, painful purpura over the distal phalanges of his toes, and no cardiac murmur. He had a history of poorly controlled type two diabetes mellitus (DM) (HBAlc of 9.5\%-11.0\% during the last twelve months). There was no preceding history of vascular access, urologic surgery, urinary tract obstruction, or urethral catheterisation. Previous medication only included metformin and gliclazide.

Intravenous flucloxacillin was commenced prior to collection of blood cultures, which subsequently failed to grow any microorganism. His diabetes was brought under control with insulin. The left axillary abscess was incised and drained and vancomycin was added to his therapy.

After 48 hours of therapy, he was still febrile. Mid stream urine and axillary pus both grew methicillinsensitive SA (MSSA) and vancomycin was ceased. Computerised tomography (CT) of the chest and abdomen revealed bilateral renal vein thrombosis (Figure 1, right and Figure 2, left), perinephric fat stranding (Figure 3) and an abscess in the right thigh which was drained surgically. Cultures from the thigh abscess also grew MSSA.

Acute kidney injury occurred in setting of sepsis and renal vein thrombosis. Creatinine rose from $84 \mathrm{umol} / \mathrm{L}$ to $138 \mathrm{umol} / \mathrm{L}$ and remained stable until discharge.

Technetium 99 Bone scan and transoesophageal echocardiography were inconclusive for evidence of primary or secondary focus of infection. He did not have personal or family history of venous thromboembolic disease. He was further assessed for hypercoaguable states, including the nephrotic syndrome. Twenty-four-hour urine contained $302 \mathrm{mg}$ of protein. Thrombophilic screen was negative for factor V Leiden, lupus anticoagulant, anticardiolipin antibodies, protein $\mathrm{C}$ and protein $\mathrm{S}$ deficiency, and prothrombin gene mutation (2010G $>$ A).

Intravenous flucloxacillin was continued for six weeks. Monitoring of C-reactive protein and white cell count showed rapid resolution to normal ranges during treatment. Anticoagulation was also commenced with initial enoxaparin followed by warfarin. CT angiogram showed resolution of renal vein thrombosis after anticoagulation for one week (Figure 4). 


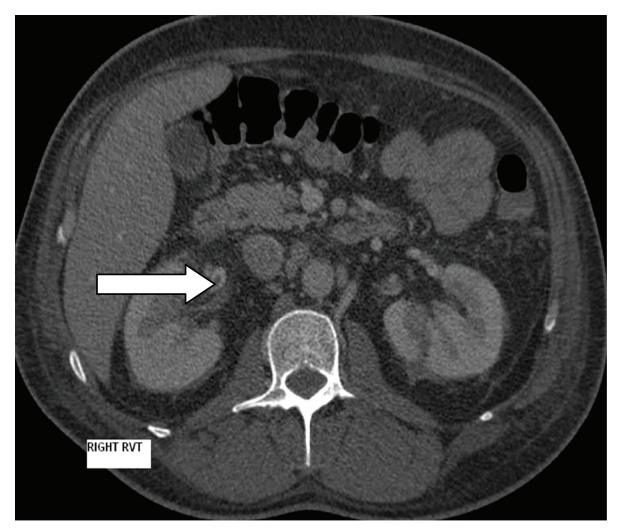

Figure 1

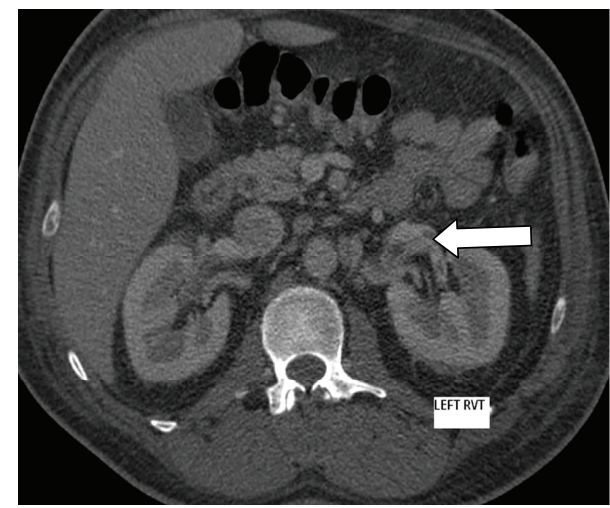

Figure 2

\section{Discussion}

Staphylococcus aureus (SA) is a commensal in 11 to 32 percent of healthy individuals and 25 percent of hospital personnel [1]. Persistently colonized persons are at an increased risk of SA infection and risk is further increased by diabetes, intravenous drug use, haemodialysis as well as other immunocompromised states including HIV $[2,3]$. Skin and related SA infections are responsible for 17 percent of cases with 14 percent 30-day mortality [4]. The incidence of staphylococcal endocarditis as a cause of staphylococcal sepsis is less than 5 percent but 30 day mortality is as high as 11.8 to 23.9 percent [4]. Staphylococcus aureus bacteraemia (SAB) and SA bacteriuria (SABU) can occur in patients following indwelling urinary catheterization (IDUC) and urologic surgery. Up to 19.5 percent, patients can develop concurrent SAB and SABU without IDUC and more likely to have MSSA with community onset [5]. Vertebral osteomyelitis and softtissue infections are also common causes of $\mathrm{SAB}$ associated with concurrent SABU [6]. Persistent SAB is associated with bacterial endocarditis (BE) in complicated $\mathrm{SAB}$ [5]. Our patient had SABU secondary to soft-tissue abscess with no evidence of persistent bacteraemia, osteomyelitis, or BE.

We conducted the literature review by using PubMed and Cochrane review using terms "staphylococcal sepsis and renal vein thrombosis."

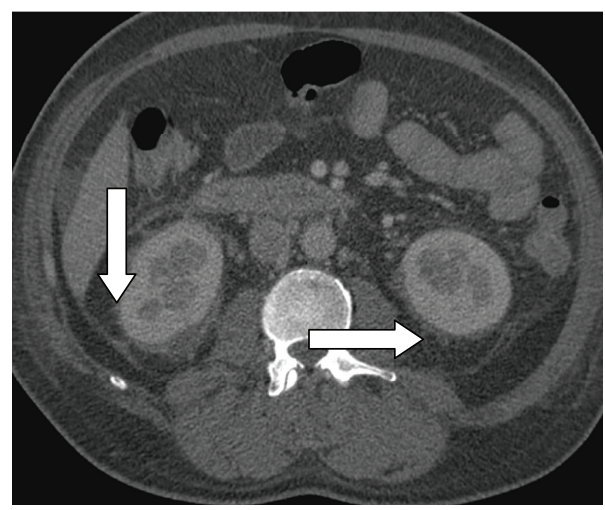

FIGURE 3: Perinephric stranding.

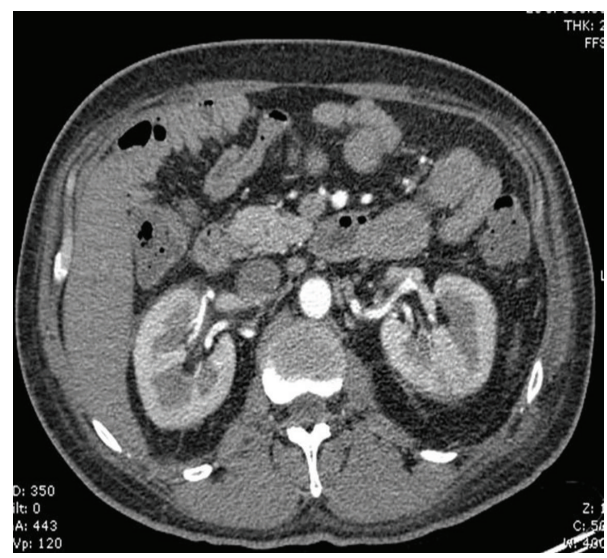

Figure 4: CT angiogram with no thrombus after 1 week of treatment.

Our patient developed bilateral pyelonephritis complicated by renal vein thrombosis in the context of SA sepsis. This followed likely seeding from an axillary abscess and in the absence of a procoagulant state or nephrotic syndrome. Renal vein thrombosis is a well-known complication of the nephrotic syndrome particularly membranous glomerulonephropathy (MGN), with prevalence of 20-60\% [7].

Renal vein thrombosis associated with pyelonephritis has become exceptionally rare since the advent of effective antibiotics [8]. Novelli et al. [9] reported right renal vein thrombosis following acute cholecystitis and pyelonephritis as with our case SA was the causative organism. Harris et al. [10] reported bilateral renal vein thrombosis from pyelonephritis but due to a Klebsiella species. Staphylococcal bacteraemia is associated with venous as well as arterial thrombosis, in the absence of prothrombotic disorders [11]. Multiple mechanisms involved in interaction of SA with various body tissues, including native and undamaged heart valves, bones, joints, and other solid organs. These interactions allow SA to seed from blood stream to other tissues. Staphylococci adhere to vascular endothelium and bind through adhesion receptor interaction [12]. A number of different adhesion molecules, including microbial surface component recognizing adhesive matrix molecules 
(MSCRAMM) such as protein A, clumping factor A (ClfA), fibronectin-binding proteins A (FnBPA), and fibronectinbinding protein $\mathrm{B}$ (FnBPB), allow SA to interact and invade human endothelium $[12,13]$.

MSCRAMM, ClfA, FnBPA, and FnBPB are not only responsible for binding and invasion of SA but also cause activation of platelet activation [14]. ClfA and FnBP bind fibrinogen allowing an interaction with platelet GPIIb/IIIa receptors and Fc $\gamma$ RIIa $[15,16]$. MSCRAMM-, ClfA-, FnBPAand FnBPB-mediated binding, invasion by $\mathrm{SA}$, and platelet activation via GPIIb/IIIa and Fc $\gamma$ RIIa is likely a mechanism leading to thrombosis.

The detection of renal vein thrombosis complicating SA sepsis posed a difficult management dilemma in our patient. Prompt treatment was important in order to preserve renal parenchyma and prevention of thromboembolism. Medical therapy included volume resuscitation, anticoagulation with prolonged antibiotic therapy, and rigorous glycaemic control. Duration of anticoagulation is generally guided by the presence or absence of reversible cause or prothrombotic state. In our case, anticoagulation had been prescribed for three months. Treating septic renal vein thrombosis with anticoagulation is not based on any clear guideline or recommendation and could plausibly be associated with increased of risk of bleeding. Our patient had been followed up regularly and had no complication at the end of the three months with stable renal function (creatinine 122 umole/L). Catheter-guided thrombolysis can be successful in selected cases with acute RVT and acute renal failure [17]. Prognosis of RVT depends on multiple prognostic factors, including baseline renal function at the onset, speed of onset, and adequacy of collaterals, underlying aetiology as well as adequacy of treatment $[18,19]$.

\section{Conclusion}

To the best of our knowledge, this is the first paper on renal vein thrombosis complicating SA sepsis from an axillary abscess. Renal vein thrombosis should be suspected in cases of SA sepsis and unexpected acute kidney injury. Prompt management of the patient's infection and also anticoagulation lead to a successful recovery.

\section{Conflict of Interests}

The authors declare that they have no conflict of interests.

\section{Authors' Contribution}

All authors have contributed to this patient's management and preparation of this paper.

\section{References}

[1] R. P. Wenzel and T. M. Perl, "The significance of nasal carriage of Staphylococcus aureus and the incidence of postoperative wound infection," Journal of Hospital Infection, vol. 31, no. 1, pp. 13-24, 1995.
[2] A. Van Belkum, N. J. Verkalk, C. P. De Vogel et al., "Reclassification of Staphylococcus aureus nasal carriage types," Journal of Infectious Diseases, vol. 199, no. 12, pp. 1820-1826, 2009.

[3] T. Weinke, R. Schiller, F. J. Fehrenbach, and H. D. Pohle, "Association between Staphylococcus aureus nasopharyngeal colonization and septicemia in patients infected with the human immunodeficiency virus," European Journal of Clinical Microbiology and Infectious Diseases, vol. 11, no. 11, pp. 985989, 1992.

[4] J. D. Turnidge, D. Kotsanas, W. Munckhof et al., "Staphylococcus aureus bacteraemia: a major cause of mortality in Australia and New Zealand," Medical Journal of Australia, vol. 191, no. 7, pp. 368-373, 2009.

[5] C. Pulcini, M. Matta, V. Mondain et al., "Concomitant Staphylococcus aureus bacteriuria is associated with complicated $S$. aureus bacteremia," Journal of Infection, vol. 59, no. 4, pp. 240246, 2009.

[6] S.-H. Choi, S.-O. Lee, J.-P. Choi et al., "The clinical significance of concurrent Staphylococcus aureus bacteriuria in patients with S. aureus bacteremia," Journal of Infection, vol. 59, no. 1, pp. 37-41, 2009.

[7] G. R. Briefel, T. Manis, and D. H. Gordon, "Recurrent renal vein thrombosis consequent to membranous glomerulonephritis," Clinical Nephrology, vol. 10, no. 1, pp. 32-37, 1978.

[8] M. F. Mamzer-Bruneel, D. Anglicheau, J. M. Correas et al., "Renal vein thrombosis: a forgotten complication of acute pyelonephritis," Presse Medicale, vol. 26, no. 28, pp. 13341336, 1997.

[9] L. Novelli, A. Raynaud, O. Pellerin, T. Carreres, and M. Sapoval, "Percutaneous manual aspiration embolectomy of renal vein thrombosis due to acute pyelonephritis," CardioVascular and Interventional Radiology, vol. 30, no. 5, pp. 1075-1078, 2007.

[10] L. A. Harris, M. J. Van Every, and L. J. Fundell, "Acute bilateral renal vein thrombosis secondary to sepsis from pyelonephritis," Journal of the Brazilian Society of Urology, vol. 38, pp. 132-134, 2012.

[11] M. C. Joshi, A. K. Baronia, R. K. Singh, and B. Poddar, "Staphylococcal sepsis presenting as pulmonary embolism," Indian Journal of Pediatrics, vol. 77, no. 7, pp. 801-802, 2010.

[12] D. C. Tompkins, V. B. Hatcher, D. Patel, G. A. Orr, L. L. Higgins, and F. D. Lowy, "A human endothelial cell membrane protein that binds Staphylococcus aureus in vitro," Journal of Clinical Investigation, vol. 85, no. 4, pp. 1248-1254, 1990.

[13] G. M. Vercelotti, D. Lussenhop, and P. K. Peterson, "Bacterial adherence to fibronectin and endothelial cells: a possible mechanism for bacterial tissue tropism," Journal of Laboratory and Clinical Medicine, vol. 103, no. 1, pp. 34-43, 1984.

[14] J. M. Patti, B. L. Allen, M. J. McGavin, and M. Hook, "MSCRAMM-medicated adherence of microorganisms to host tissues," Annual Review of Microbiology, vol. 48, pp. 585617, 1994.

[15] S. W. Kerrigan, N. Clarke, A. Loughman, G. Meade, T. J. Foster, and D. Cox, "Molecular basis for Staphylococcus aureusmediated platelet aggregate formation under arterial shear in vitro," Arteriosclerosis, Thrombosis, and Vascular Biology, vol. 28, no. 2, pp. 335-340, 2008.

[16] J. R. Fitzgerald, A. Loughman, F. Keane et al., "Fibronectinbinding proteins of Staphylococcus aureus mediate activation of human platelets via fibrinogen and fibronectin bridges to integrin GPIIb/IIIa and IgG binding to the Fc $\gamma$ RIIa receptor," Molecular Microbiology, vol. 59, no. 1, pp. 212-230, 2006. 
[17] K. K. Lam and C. C. Lui, "Successful treatment of acute inferior vena cava and unilateral renal vein thrombosis by local infusion of recombinant tissue plasminogen activator," American Journal of Kidney Diseases, vol. 32, no. 6, pp. 10751079, 1998.

[18] M. Laville, D. Aguilera, P. J. Maillet, M. Labeeuw, O. Madonna, and P. Zech, "The prognosis of renal vein thrombosis: a reevaluation of 27 cases," Nephrology Dialysis Transplantation, vol. 3, no. 3, pp. 247-256, 1988.

[19] M. Asghar, K. Ahmed, S. S. Shah, M. K. Siddique, P. Dasgupta, and M. S. Khan, "Renal vein thrombosis," European Journal of Vascular and Endovascular Surgery, vol. 34, no. 2, pp. 217-223, 2007. 


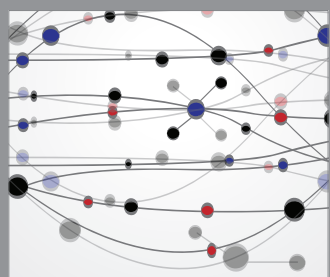

The Scientific World Journal
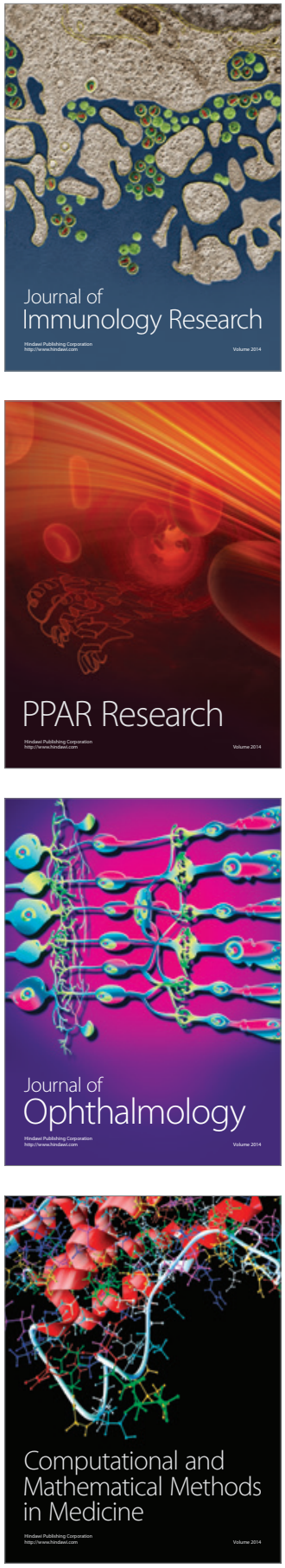

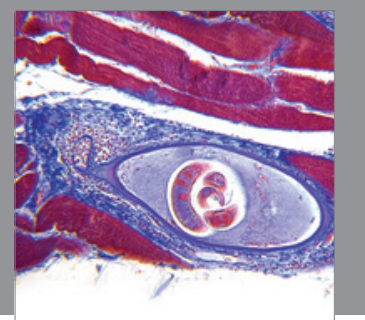

Gastroenterology

Research and Practice
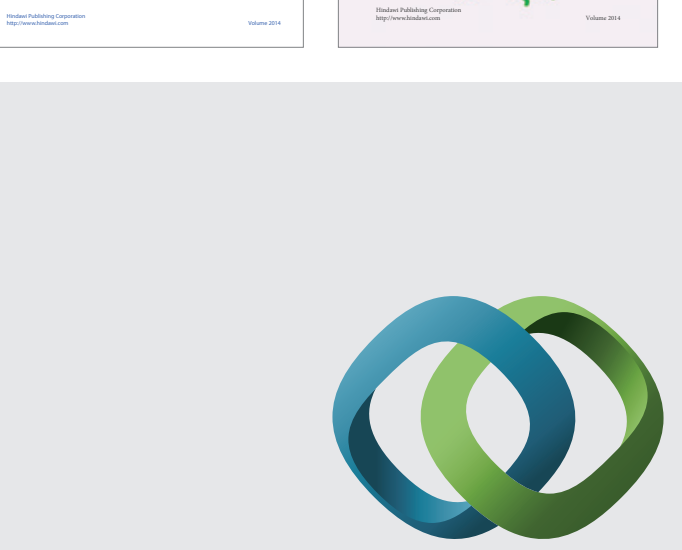

\section{Hindawi}

Submit your manuscripts at

http://www.hindawi.com
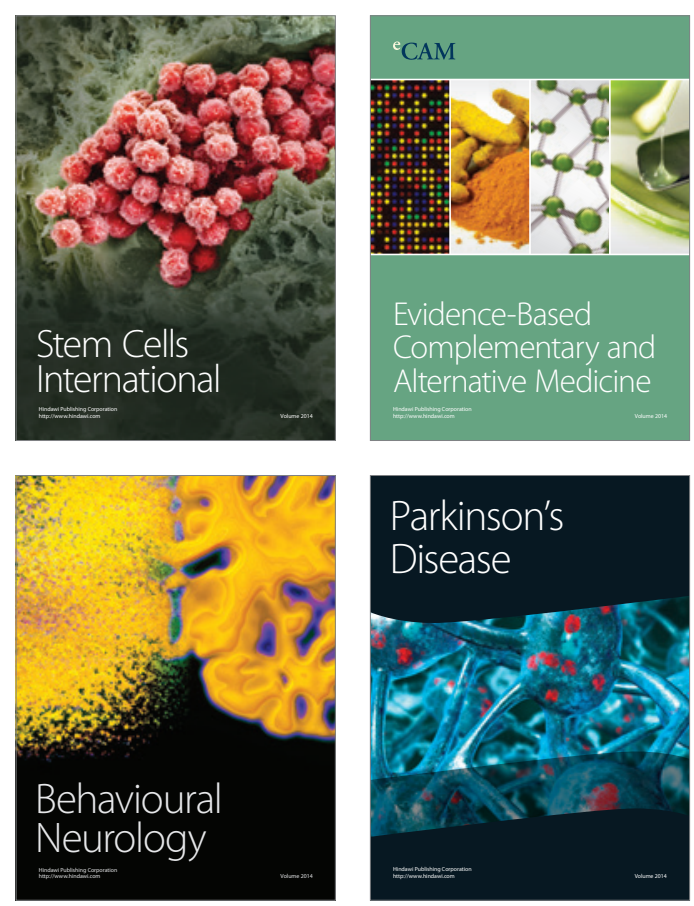

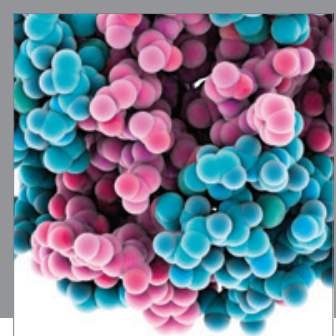

Journal of
Diabetes Research

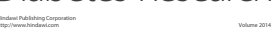

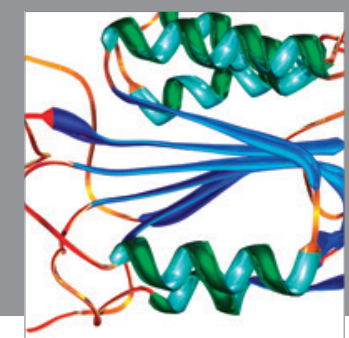

Disease Markers
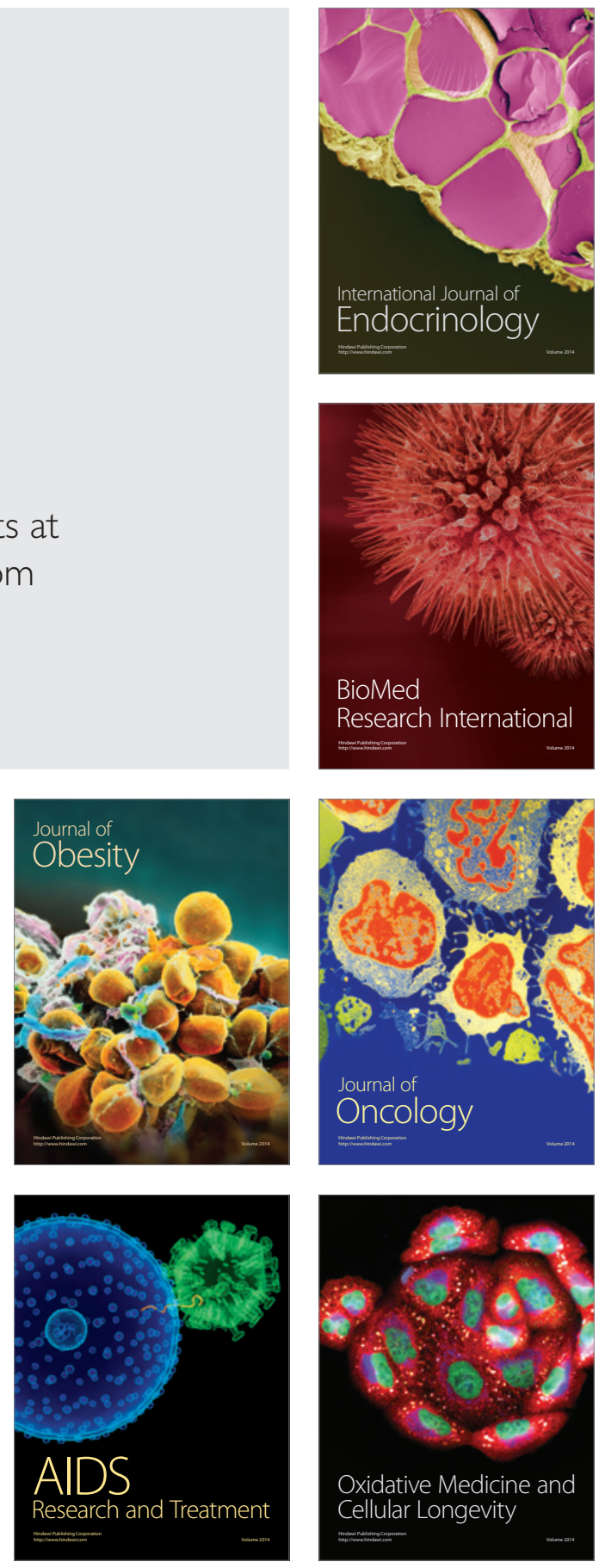